\title{
СОЦИАЛЬНЫЕ УСЛУГИ В СИСТЕМЕ РЕГИОНАЛЬНОГО СОЦИАЛЬНО-ЭКОНОМИЧЕСКОГО КОМПЛЕКСА
}

\author{
(c) 2020 Рунов Александр Владимирович \\ кандидат экономических наук \\ Управляющий Краснодарским региональным отделением \\ Фонда социального страхования Российской Федерации, Россия, Краснодар \\ E-mail: av.runov_65@mail.ru
}

\begin{abstract}
Одной из ключевых задач формирующейся системы стратегического планирования выступает установка на формирование сбалансированного социально-экономического комплекса субъектов Федерации. В числе важнейших составляющих такого комплекса - сегмент социальных услуг, функциональная роль которого состоит в улучшении количественных и качественных характеристик человеческого капитала в экономике региона. В статье рассматриваются основные проблемы развития комплекса социальных услуг в экономике региона. Делается акцент на адекватное отражение проблем и перспектив сектора социальных услуг в стратегиях социально-экономического развития субъектов Российской Федерации.
\end{abstract}

Ключевые слова: социальные услуги, экономика регионов, государственное регулирование, стратегическое планирование.

\section{Социальные услуги: основные признаки}

Роль сферы социальных услуг в социальноэкономическом комплексе субъекта Федерации можно рассматривать с нескольких позиций. Одна из них - ее функциональное определение. Здесь также существует несколько подходов к тому, что следует понимать под «социальными услугами». Один из этих подходов - экономический, который характеризует эту сферу как систему услуг, непосредственно нацеленных на воспроизводство человеческого капитала. С правовой точки зрения определение (классификация) социальных услуг даны в Федеральном законе «Об основах социального обслуживания граждан в Российской Федерации» [8], ст.20.

Роль сферы услуг в социально-экономическом комплексе субъекта Федерации можно рассматривать также с позиции, которую следует охарактеризовать как «управленческая». С этой точки зрения сферу социальных услуг в региональном социально-экономическом комплексе следует ограничить тем ее сегментом, который находится в пределах регулятивных, бюджетных и иных полномочий субъекта Федерации. Наконец, роль и структуру сферы социальных услуг можно рассматривать с институциональной точки зрения, когда все отрасли этой сферы экономики региона делятся на публичный сектор (федеральные, региональные и муниципальные учреждения социальной сферы) и частнопред- принимательский сектор.

Некоторое промежуточное положение в этом смысле занимает тот сегмент социальных услуг (особенно в сфере здравоохранения и образования), которые оказываются на материальной базе государственных и муниципальных учреждений, но на коммерческой основе. Кроме того, на «стыке» двух институциональных структур социальных услуг в настоящее время формируется «ниша» тех форм социального обслуживания граждан, которая функционирует на началах государственно-частного и муниципального частного партнерства [2]. Характерным примером такого взаимовыгодного (для государства, бизнеса и самих граждан) партнерства может служить подключение частных фирм, действующих в сфере здравоохранения, к оказанию услуг по системе обязательного медицинского страхования [4].

Таким образом, переход к рыночной экономике делает сферу социальных услуг, в том числе, и на региональном уровне, вполне легитимным «полем» для всех видов предпринимательской деятельности (инвестирование, оказание платных услуг, аренда, франшиза и пр.). Это «поле» как показывает практика, в полной мере затрагивает и деятельность субъектов малого и среднего предпринимательства (МСП). Таковое - и в больших городах, и в отделанной местности восполняет для населения дефицит социальных 
услуг, чаще всего связанный с недостаточной гибкостью в организации социального обслуживания граждан, характерной для крупных государственных и муниципальных учреждений. Кроме того, деятельность малых форм хозяйствования в сфере социальных услуг создает в этом сегменте экономики, причем на местном уровне, достаточно развитую конкретную среду, позволяющую удерживать стоимость и качество таких услуг от всех прочих провайдеров на приемлемом для потребителей уровне.

Есть и еще ряд позитивных эффектов от «включения» МСП в предоставление социальных услуг населению. Это, в частности, и дополнительные рабочие места и во многих случаях дополнительные доходы для местных бюджетов. Как показывает практика, у субъектов МСП провайдеров социальных услуг на местах традиционно складывается «своя» система клиентов; такие предприятия часто становятся центрами социального общения и взаимопомощи, движения волонтеров, досуговыми центрами и пр. Не случайно, экспертами отмечается тот факт, что деятельность малого бизнеса в сфере социальных услуг способствует снижению социальной напряженности в самых различных поселениях страны [1;7].

Следует, однако, различать, в т.ч. и в сфере МСП, социальное предпринимательство (в том числе, и среде субъектов МСП) и предпринимательство в социальной сфере, хотя и есть различные формы их взаимопроникновения [6]. Социальное предпринимательство не связано с тем или иным видом экономической деятельности; оно, как правило, осуществляется с целью обеспечения максимальной доступности жизненных благ, рабочих мест и источников заработка для наименее обеспеченной, защищенной части населения и во многом смыкается с благотворительностью. Недавно понятие «социального предпринимательства» получило официальное узаконение. Ст. 3 Федерального закона «О развитии малого и среднего предпринимательства в Российской Федерации» от 24 июля 2007 г. № 209-Ф3 [9], теперь определяет «социальное предпринимательство» как предпринимательскую деятельность, направленную на достижение общественно полезных целей и способствующую решению социальных проблем граждан.

Предпринимательство в сфере социальных услуг характеризуется иной трактовкой понятия «социальности». Такое предпринимательство, как правило, ориентируется на критерии спроса и предложения, и соответственно, максимизации эффекта в конкретной рыночной ситуации. Разумеется, и здесь сохраняется весомая мера государственного воздействия. В прямой форме оно осуществляется за счет действующей жесткой практики лицензирования и контроля частных предприятий в сфере социального обслуживания, особенно в сфере здравоохранения и образования. Большая роль в формировании конкурентной среды среди провайдеров социальных услуг играют и субъекты МСП, занятые оказанию социальных услуг населению.

Социальные услуги как объект стратегчческого планирования

В настоящее время основным инструментом целенаправленного формирования и управления сферой социальных услуг в экономике регионов России выступает практика стратегического планирования. Однако как отмечали многие эксперты, регулирующий эту практику 172-й Ф3 о стратегическом планировании [10] недостаточно уделяет внимания долгосрочному видению проблем социальных услуг на уровне субъектов Федерации, а также путям их решения в стратегической перспективе развития регионов [3].

В отсутствие «базовой» Стратегии социальноэкономического развития Российской Федерации, социальные услуги как объект стратегирования на федеральном уровне попадают под регулирующее воздействие по двум направлениям. Во-первых, это блок федеральных государственных программ «Новое качество жизни» (10 программ со сроком действия до 2024-2025 гг.). Во-вторых, это система национальных проектов, инициированных в соответствии с Указом Президента РФ «О национальных целях и стратегических задачах развития Российской Федерации на период до 2024 года» [11]. В отличие от 172-го Ф3, многие национальные проекты имеют четко выраженную социальную окраску. Это проекты «Здравоохранение», «Образование», «Демография», «Культура», «Жилье и городская среда», «Экология». Существенную связь с системой социальных услуг имеют и такие проекты, как «Малое и среднее предпринимательство и поддержка индивидуальной предпринимательской инициативы», «Производительность труда и поддержка занятости». Проблема, однако, в том, что национальные проекты как инструмент постановки и достижения долговременных целей в экономической и социальной сфере не отра- 
жены в 172-м Ф3 о стратегическом планировании, вследствие чего их связь со стратегиями социально-экономического развития субъектов Российской Федерации не просматривается достаточно четко.

Между тем, именно эти стратегии наиболее полно отражают место и перспективы развития комплекса социальных услуг в экономике регионов. Как и ряд иных аспектов социальноэкономического развития субъектов Федерации, проблемы сферы социальных услуг отражаются в их стратегиях с двух позиций. Во-первых, с точки зрения общего предвидения желаемых для региона количественных и качественных параметров функционирования сферы социальных услуг. Во-вторых, с точки среди политики развития сферы социальных услуг со стороны самого субъекта Федерации. Под прямое воздействие в этом случае падает лишь тот сегмент сферы социальных услуг, который регулируется и бюджетируется органами исполнительной власти субъекта Федерации. Особо заметна эта ситуация в сфере здравоохранения, где в пределах одной территории помимо частных могут действовать федеральные, региональные и муниципальные учреждения этого профиля. Видимо, это объясняет тот факт, что, несмотря на активное совершенствование методологии и практики стратегического планирования, в т.ч. и на региональном уровне, системного стратегирования развития сферы социальных услуг в субъектах Федерации пока не осуществляется.

Анализ целого действующих стратегий социально-экономического развития субъектов Федерации показывает, что формально все они декларируют сохранение и приумножение человеческого капитала как их основную цель. Однако политика регионов по развитию сферы услуг в их стратегических документах, как правило, дается фрагментарно, несистемно, без акцента на критерии и механизмы доведения объема и качества социальных услуг до тех требований, которые диктуются, прежде всего, трендом расширенного воспроизводства человеческого капитала экономики региона.

Стратегии отражают в основном уже проделанную работу и намечаемые ориентиры по совершенствованию материальной базы сферы социальных услуг экономики субъекта Федерации, по укреплению кадрового потенциала этой сфе- ры и пр. А вот целостного восприятия особенностей целей и инструментов развития сферы услуг при этом не формируется. Отсутствуют перспективные наработки по институциональной структуре сферы социальных услуг, по развитию в этой сфере практики государственно-частного и муниципально-частного партнерства. Даже самые поздние по времени принятия (2019 г.) стратегии субъектов Федерации не учитывают того, что предполагается реализовать в сфере социальных услуг экономики того или иного региона на основе системы национальных проектов. К настоящему времени реализовано положение национального проекта «Малое и среднее предпринимательство и поддержка индивидуальной предпринимательской инициативы» в части правового регулирования института социального предпринимательства, но, к сожалению, специального акцента на развитие МСП в сфере социальных услуг данный проект не содержит.

В настоящее время намечается переработка такого важного документа, как «Методические рекомендации по разработке и корректировке стратегии социально-экономического развития субъекта Российской Федерации и плана мероприятий по ее реализации» [5]. Данный документ рекомендует включать в региональные стратегии раздел, «содержащий основные направления развития человеческого капитала и социальной сферы субъекта Российской Федерации». Казалось бы, здесь видна прямая связь с развитием социальных услуг. Однако при последующем изложении этого вектора регионального стратегирования в Методических рекомендациях проблема «развития человеческого капитала» как основа стратегического видения развития сектора социальных услуг исчезает и все сводится к традиционным параметрам, определяющим уровень и качество жизни населения субъекта Федерации. Как мы полагаем, что доработке Методических рекомендаций, содержательные акценты данного блока должны получить конкретную проработку, а категория человеческого капитала - при разработке соответствующих методологических подходов - из формальной отсылки должна занять место исходной точки стратегирования всех параметров развития сферы социальных услуг в экономике региона, включая и возможную роль сектора МСП. 


\section{Библиографический список}

1. Бардасова Э.В. Продвижение малых форм бизнеса в сфере услуг с целью снижения социальной напряженности в регионах // Ученые записки Российской Академии предпринимательства. 2015. № 43. С.224-230.

2. Барков А.В., Серова О. А. Государственно-частное партнерство на рынке социальных услуг в свете развития социального предпринимательства: проблемы гармонизации правового регулирования // Вестник Пермского университета. 2016. № 33. С.268-280.

3. Гагарина Г.Ю., Мирошников С.Н. Некоторые вопросы управления социально-экономическим развитием субъектов Российской Федерации на основе системы стратегического планирования // Управленческое консультирование. 2018. № 12 (120). С. 79-90.

4. Косенко О.Ю. К вопросу о роли негосударственных организаций в оказании социальных услуг населению // Инновационная наука. 2016. № 3-1. С.145-148.

5. Приказ Министерства экономического развития РФ от 23 марта 2017 г. № 132 «Об утверждении Методических рекомендаций по разработке и корректировке стратегии социально-экономического развития субъекта Российской Федерации и плана мероприятий по ее реализации». [Электронный ресурc]. URL: https:// www.garant.ru/products/ipo/prime/doc/71542236/\#1000.

6. Рожкова Е.В., Мингачева Л.Р. Услуги социальной сферы как объект социального предпринимательства // Экономика устойчивого развития. 2019. № 1 (37). С.217-220.

7. Руденко Л.Г. Социально-экономическая роль малого предпринимательства сферы услуг в поступательном развитии России // Актуальные проблемы экономики и права. 2016. Т.10. № 1 (37). С.62-70.

8. Федеральный закон от 28 декабря 2013 г. № 442 -Ф3 «Об основах социального обслуживания граждан в Российской Федерации». [Электронный ресурс] URL: http://www.consultant.ru/document/cons_doc_LAW_156558/ fc5ba61658eaba06fc1242940c47c8d070ac6d22/.

9. Федеральный закон от 24 июля 2007 г. № 209-Ф3 «О развитии малого и среднего предпринимательства в Российской Федерации». [Электронный ресурс] URL: http://www.consultant.ru/document/cons_doc_LAW_52144/.

10. Федеральный закон от 28 июня 2014 г. № 172-Ф3 «О стратегическом планировании в Российской Федерации» [Электронный ресурc]. URL: http://www.consultant.ru/document/cons_doc_LAW_164841/.

11. Указ Президента РФ от 7 мая 2018 года № 208 «О национальных целях и стратегических задачах развития Российской Федерации на период до 2024 года». [Электронный ресурс] URL: http://kremlin.ru/events/ president/news/57425. 